\author{
Maestría en Economía \\ Facultad de Ciencias Económicas \\ Universidad Nacional de La Plata
}

TESIS DE MAESTRIA

\author{
ALUMNO \\ Luciana Galeano
}

TITULO

Estructura Productiva y Retornos a la Educación: Evidencia para América

Latina

DIRECTOR

Leonardo Gasparini

FECHA DE DEFENSA

$3 / 23 / 2018$ 


\title{
Estructura productiva y retornos a la educación: evidencia para América Latina
}

\author{
Luciana Galeano
}

\author{
Tesis de Maestría \\ Maestría en Economía \\ Universidad Nacional de La Plata
}

\author{
Director: \\ Leonardo Gasparini
}

23 de Marzo de 2018

Códigos JEL: D31, I26, J21, J31 


\title{
Estructura productiva y retornos a la educación: evidencia para
}

\section{América Latina*}

\author{
Luciana Galeano ${ }^{* *}$
}

\begin{abstract}
Resumen
Este trabajo estudia la evolución de las primas salariales por nivel educativo y su relación con la estructura productiva para dieciséis países de América Latina, utilizando datos de encuestas de hogares y de cuentas nacionales en el período 1991-2015. La evidencia presentada sugiere que el cambio en la estructura productiva es un factor relevante para dar cuenta de la dinámica de la desigualdad salarial. En particular, cuando crece la participación en el valor agregado de los sectores más intensivos en trabajo calificado, aumentan significativamente las primas salariales por educación.
\end{abstract}

\begin{abstract}
This paper studies the evolution of skill premiums and its relationship with the productive structure for sixteen countries in Latin America, using data from household surveys and national accounts in the period 1991-2015. The evidence presented suggests that the change in the productive structure is a relevant factor to account for the dynamics of wage inequality. In particular, when the share in the value added of sectors that are more intensive in high-skill labor increases, the skill premium increases significantly.
\end{abstract}

Códigos JEL: D31, I26, J21, J31

Palabras clave: prima salarial; estructura productiva; América Latina

\footnotetext{
* Este trabajo constituye mi tesis de Maestría en Economía de la Universidad Nacional de La Plata, dirigida por Leonardo Gasparini (CEDLAS-UNLP y CONICET). El trabajo forma parte de un proyecto de investigación más amplio en el que trabajamos en conjunto con Leonardo Gasparini y Matías Ciaschi (CEDLAS-UNLP), a quienes agradezco enormemente por sus valiosas contribuciones y apoyo. Mis agradecimientos también a Pablo Glüzmann por los productivos intercambios. Cualquier error del presente trabajo es de mi entera responsabilidad.

"* Centro de Estudios Distributivos, Laborales y Sociales (CEDLAS), Universidad Nacional de La Plata. Email: luciana.galeano@econo.unlp.edu.ar
} 


\section{Índice}

1. Introducción............................................................. 3

2. Antecedentes empíricos................................................ 8

3. Datos y metodología ....................................................... 10

4. Resultados.................................................................... 16

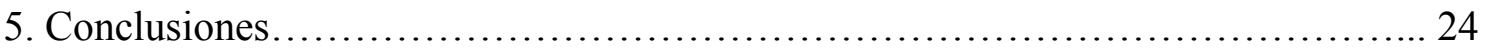

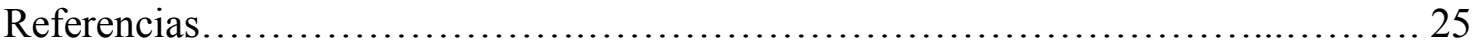

Apéndice.................................................................. 27 


\section{Introducción}

El análisis de la desigualdad de ingresos y sus determinantes es uno de los temas más discutidos a nivel internacional, sobre todo en el contexto de los países de Latinoamérica, una de las regiones más desiguales del mundo. Si bien aún la desigualdad en la región permanece a niveles elevados respecto a la de los países desarrollados, en la década de los dos mil América Latina experimentó una caída sustancial en sus niveles de desigualdad de ingresos. Esto ocurrió luego de lo acontecido en la década de los noventa cuando, de la mano de procesos de apertura, privatización y liberalización económica, la dispersión de ingresos se incrementó. Sin embargo, la evidencia más reciente indica la existencia de una desaceleración en la caída de la desigualdad de ingresos en la región en los últimos años e incluso un incipiente crecimiento de la misma en algunos países latinoamericanos (Gasparini et al., 2016). En resumen, la desigualdad de ingresos promedio en América Latina experimentó una evolución como la que se representa en la Figura 1.

\section{Figura 1.}

Evolución del Índice de Gini en el ingreso per cápita familiar promedio para América Latina.

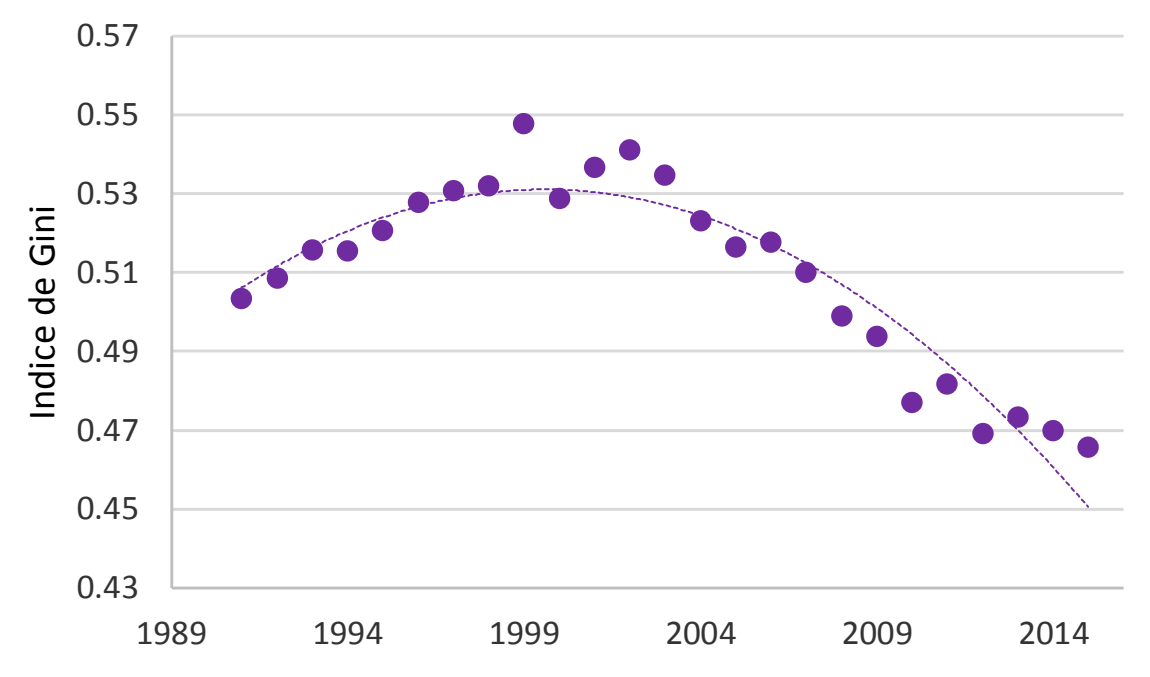

Fuente: elaboración propia en base a SEDLAC (CEDLAS y Banco Mundial).

Otro hecho relevante ocurrido desde 1991 hasta la actualidad es el cambio en la importancia de los diferentes sectores económicos en el valor agregado total de la 
economía. La Figura 2 muestra la evolución de la participación en el valor agregado de los cinco sectores más intensivos en trabajo de alta calificación. ${ }^{1}$

\section{Figura 2}

Participación en el valor agregado de los sectores más intensivos en trabajo de alta calificación.

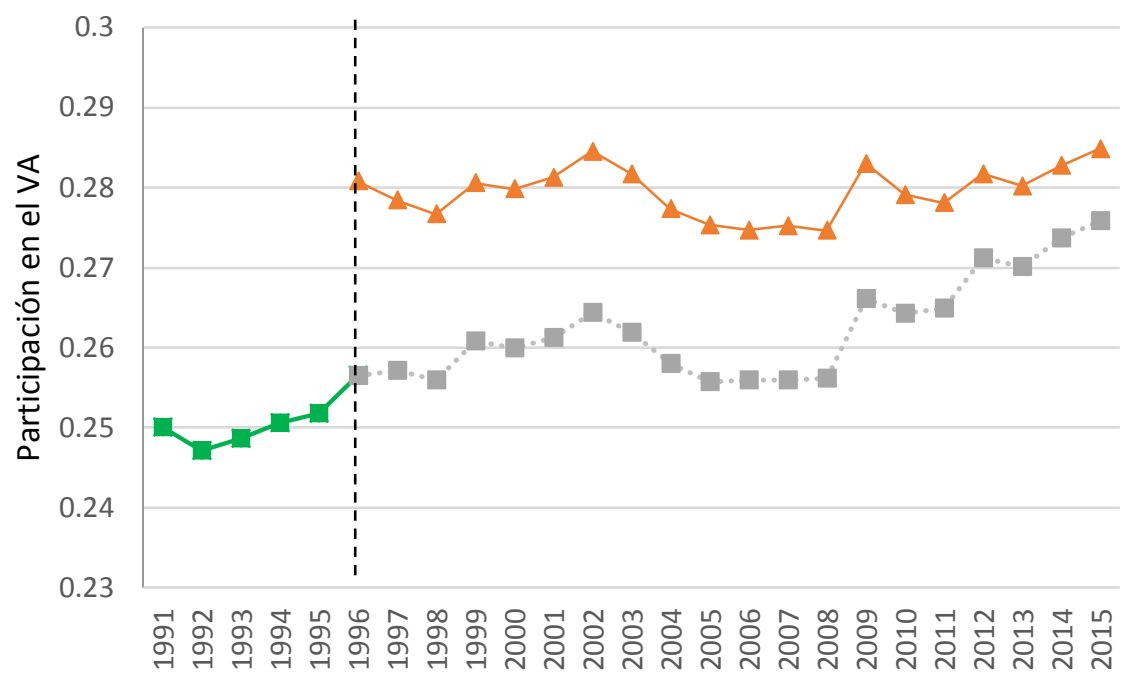

Fuente: elaboración propia en base a datos de cuentas nacionales, SEDLAC (CEDLAS y Banco Mundial).

Nota: dentro de cada país se toma como intensivo en trabajo de alta calificación a los cinco sectores con mayor participación de trabajadores con nivel terciario completo para el promedio de los años de la muestra. La línea con triángulos corresponde a la muestra completa. La línea con cuadrados elimina los siguientes países por falta de datos en varios años de los noventa: Brasil, Chile, México, Panamá, Perú y Uruguay.

La línea superior, con triángulos, corresponde a la muestra completa. Para ver cómo evoluciona la participación en el valor agregado de los sectores más intensivos en trabajo calificado en los noventa, se grafica una serie alternativa que se queda solo con los países que tienen suficientes datos en todo el período ${ }^{2}$. De la Figura 2 se desprende que en los años noventa creció significativamente la participación de los sectores intensivos en trabajo calificado. En este período diversos factores ligados a las decisiones de política económica y al contexto mundial propiciaron una mayor

\footnotetext{
${ }^{1}$ Dentro de cada país se toma como intensivo en trabajo de alta calificación a los cinco sectores con mayor participación de trabajadores con nivel terciario completo para el promedio de los años de la muestra. Hay 4 sectores para los cuales todos los países de la muestra coinciden en tomarlos como intensivos en alta calificación (Intermediación Financiera; Actividades inmobiliarias, empresariales y de alquiler; Educación y Salud). El quinto sector en once de los dieciséis países es Administración pública y defensa.

${ }^{2}$ Esto implica quedarse con la siguiente submuestra: Argentina, Bolivia, Colombia, Costa Rica, Ecuador, El Salvador, Honduras, Paraguay, República Dominicana y Venezuela.
} 
preponderancia de los sectores intensivos en trabajo calificado en los países latinoamericanos. En efecto, al menos para los países de la submuestra con datos genuinos en los noventa, dichos sectores incrementaron su participación en el producto total en 1.7 puntos porcentuales entre los años 1992 y 2002.

En contraste, la dinámica de cambio estructural en la primera década de este siglo fue diferente. Tomando la muestra completa, entre 2002 y 2008 la participación de los sectores intensivos en trabajo calificado cayó en un punto porcentual en un contexto de recuperación económica y términos de intercambio altos para la región. Por último, luego de la crisis internacional de 2008/2009 y hasta la actualidad, la importancia de los sectores intensivos en trabajo calificado ha vuelto a incrementarse, aunque más moderadamente (1 pp entre 2008 y 2015).

Por otro lado, en la Figura 3 se puede observar cómo en la mayoría de los quince sectores se produjo un crecimiento en la participación del trabajo calificado en el empleo total para el promedio de América Latina.

\section{Figura 3}

Participación del empleo calificado en el empleo total - promedios por década para América Latina.

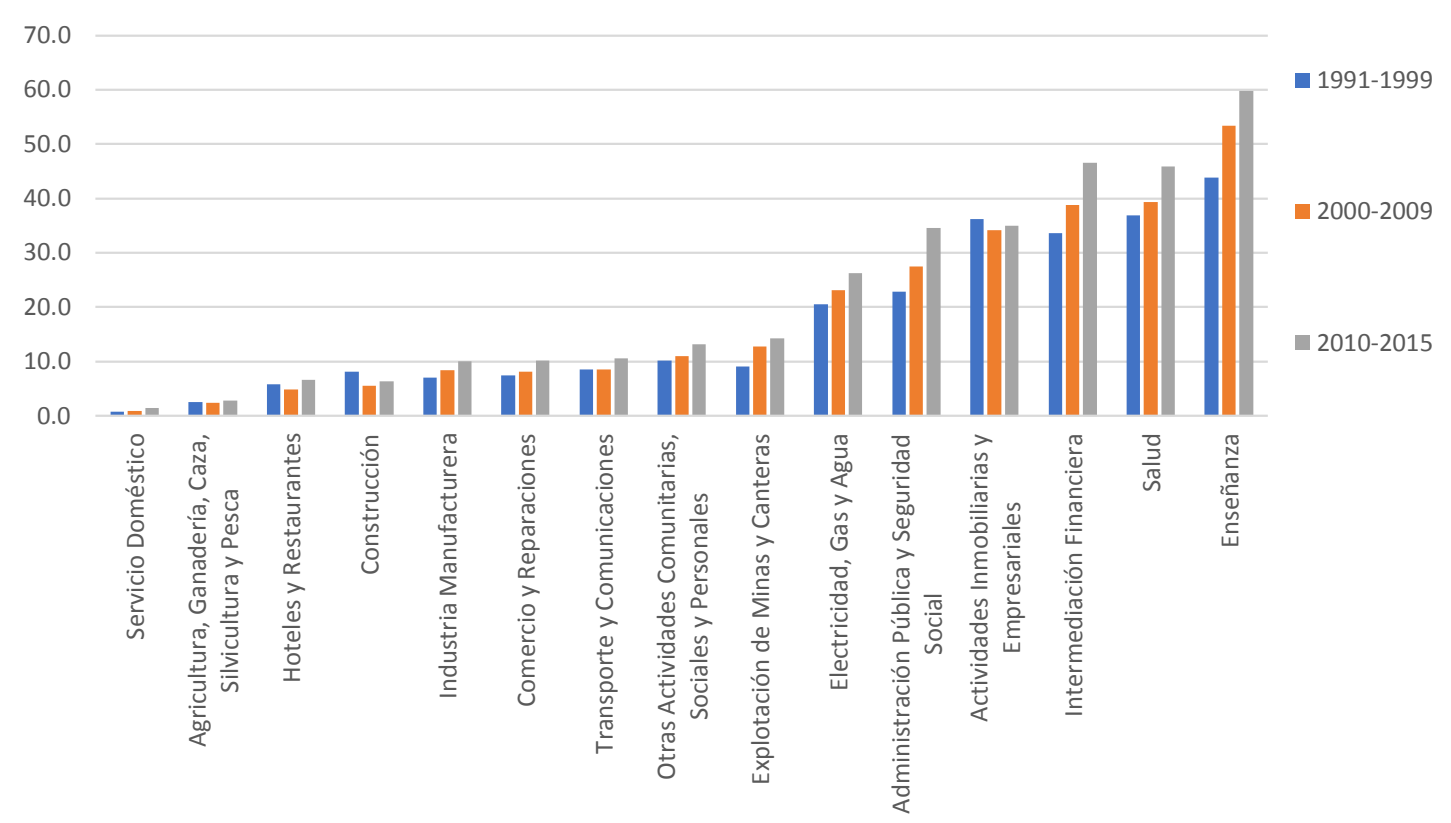

Fuente: elaboración propia en base a SEDLAC (CEDLAS y Banco Mundial). 
Por lo tanto, no solo ocurrió que aquellos sectores que utilizan más intensivamente el trabajo calificado aumentaron su participación en el producto total, sino también que, en términos generales, aumentó el uso del trabajo calificado en el empleo total en todos los sectores.

Cabe destacar de la observación de las Figuras 1 y 2 que en América Latina la desigualdad de ingresos y la participación de sectores intensivos en trabajo calificado en el producto total parecieran compartir ciertos patrones en cuanto a su evolución, aunque existen importantes diferencias en la magnitud de dichos cambios. El incremento en el índice de Gini durante los años noventa parece estar acompañado de una mayor participación en el valor agregado de sectores intensivos en trabajo calificado. Cuando esta última comienza a decrecer en la primera década de los años dos mil, la desigualdad de ingresos acompaña aún más fuertemente dicha tendencia. Por último, la recuperación de la participación de este tipo de sectores en las economías latinoamericanas puede unirse al reciente estancamiento en la caída de la desigualdad en la región. Estos hechos han motivado a indagar en qué medida la estructura productiva de las economías de América Latina está asociada con la evolución de la desigualdad de ingresos entre los trabajadores de alta calificación y los no calificados.

Existe amplia literatura que reporta cómo los componentes del ingreso relacionados a la política fiscal y las transferencias representan factores importantes a la hora de analizar las dinámicas de la desigualdad (en efecto, las transferencias cumplieron un rol significativamente relevante en disminuir la dispersión de ingresos en los años dos mil). En este trabajo se restringe el análisis a lo acontecido con la dispersión salarial en el mercado laboral para poder analizar las relaciones entre el cambio en la estructura productiva de estas economías y las remuneraciones a los diferentes tipos de trabajadores $^{3}$, dado que los ingresos laborales representan el principal componente de ingreso total en los hogares latinoamericanos (Gasparini, Cruces y Tornarolli, 2011).

El estudio de las dinámicas de la desigualdad en el mercado laboral se realiza partiendo del análisis de la literatura de "carrera entre educación y tecnología". En este contexo, se evalúa en qué medida factores de oferta y demanda poseen relevancia a la hora de explicar las dinámicas de primas salariales entre calificados y no calificados. Atendiendo al hecho de que la literatura identifica que los factores ligados a la oferta

\footnotetext{
${ }^{3}$ En particular, de los calificados vs. no calificados.
} 
explican solo una pequeña parte de las dinámicas salariales (Galiani et al., 2017), el foco se ubica en uno de los potenciales determinantes de la demanda relativa entre trabajadores: la estructura productiva. En particular, se evalúa en qué medida los shocks de demanda que llevan a un crecimiento diferencial de sectores económicos con diferente intensidad de uso de cada tipo de trabajo afectan las primas salariales. Por ejemplo, si existiera un crecimiento en la demanda de productos de sectores más intensivos en trabajo calificado, el mercado laboral tendería, en principio, hacia un equilibrio con mayores primas salariales por educación.

Este documento se estructura de la siguiente manera. La sección 2 describe la evidencia existente en la literatura sobre primas salariales y estructura productiva. La sección 3 describe las fuentes de datos y la metodología utilizada. La sección 4 muestra los principales resultados, y la sección 5 concluye. 


\section{Antecedentes empíricos}

Existen numerosos trabajos en la literatura que buscan explicar los determinantes de las primas salariales que reciben los trabajadores de alta calificación en relación a trabajadores no calificados.

Galiani et al. (2017) estudian la evolución de los diferenciales salariales y de la oferta de trabajadores por nivel educativo para dieciséis países de América Latina en el período 1991-2013. Encuentran un patrón de crecimiento constante en la oferta relativa del trabajo calificado y semi calificado en dicho período. Mientras que los retornos a la educación secundaria bajaron, los retornos a la educación terciaria muestran un crecimiento en los noventa, caída fuerte en los dos mil y desaceleración a partir de 2010. Por ende, concluyen que los factores por el lado de la oferta tienen poder limitado en relación a los factores ligados a la demanda para explicar los cambios en la prima salarial por educación.

Fernandez y Messina (2017) atribuyen gran parte de la disminución de la desigualdad de ingresos de Argentina, Brasil y Chile en los dos mil a la reducción en las primas de experiencia en la cola superior de la distribución (90/50) y la disminución en los retornos a la educación en la cola inferior (50/10). Según los autores, la oferta relativa es importante para explicar los cambios en dichas primas, mientras que las tendencias de la demanda relativa favorecieron al trabajo de alta calificación en los noventa y a los de baja calificación en los dos mil. A su vez, dicen que los cambios en el salario mínimo y las mejoras en los términos de intercambio son clave para explicar estas tendencias en la demanda relativa.

Por otro lado, existe literatura que trata de explicar el efecto de cambios estructurales sobre distintas medidas de desigualdad. Martorano y Sanfilippo (2014) analizan los determinantes de largo plazo de la brecha educativa en el sector manufacturero para un grupo de países del Este Asiático que han experimentado rápidas transformaciones estructurales en las últimas décadas. Encuentran que cambios estructurales dentro de las manufacturas en favor de la participación de trabajadores de alta calificación son fuertes determinantes de la prima salarial. Para medir el cambio estructural, los autores tienen en cuenta la participación de los sectores en el valor agregado manufacturero así como la dotación de capital por trabajador de los mismos. A su vez, destacan que el efecto 
sobre la desigualdad salarial puede aminorarse, incluso en una economía abierta, si se acompaña el cambio estructural con políticas educativas bien diseñadas, manejo prudente de la macroeconomía y políticas selectivas hacia el capital extranjero.

En la misma línea, Buera et al. (2015) documentan para países desarrollados que aumentos en el Producto Bruto Interno per cápita se asocian a cambios en la composición de valor agregado hacia sectores intensivos en trabajo de alta calificación. El desarrollo lleva a aumentar la demanda por trabajo calificado, lo que según los autores explica un 30\% del aumento en el skill premium en Estados Unidos en el período 1977-2005.

Gustafsson y Johansson (1999) analizan información de dieciséis países industrializados para el período 1966-1994 y encuentran que uno de los factores que aumentan la desigualdad de ingresos (medida por el coeficiente de Gini sobre el ingreso equivalente disponible) es un sector industrial reducido.

Rendall (2013), por su parte, examina el efecto del cambio estructural sobre la brecha salarial por género en Brasil, México, India y Tailandia en el período 1987-2008. Encuentra que el cambio estructural disminuye la demanda de atributos físicos y por ende reduce las disparidades de género, y que los países con mayores requerimientos físicos de trabajo tienen la mayor desigualdad por género, tanto en salario como en participación.

En otra línea de investigación, Rodrik y McMillan (2011) estudian los factores que influyen sobre el hecho de que el cambio en la estructura productiva pueda llevar a un crecimiento de la productividad global de la economía. Para empezar, los autores documentan las brechas de productividad laboral en varios países en desarrollo, y argumentan que los flujos de trabajo desde actividades de baja productividad hacia actividades de alta productividad son un factor clave para el desarrollo. Luego encuentran que los factores que ayudan a determinar si el cambio estructural contribuye al crecimiento de la productividad son la importancia relativa de los recursos naturales en las exportaciones, competitividad del tipo de cambio y flexibilidad en el mercado laboral. 


\section{Datos y metodología}

En este trabajo se pretenden evaluar los efectos del cambio en la estructura productiva sobre la brecha educativa para dieciséis países de América Latina ${ }^{4}$ en el período 19912015. Las principales fuentes de datos son las encuestas de hogares de los distintos países, procesadas siguiendo el procedimiento que utilizan el Centro de Estudios Distributivos, Laborales y Sociales (CEDLAS) y el Banco Mundial (BM) en el proyecto Socio-Economic Database for Latin America and the Caribbean (SEDLAC), lo que permite que las encuestas sean comparables no solo intertemporalmente, sino también entre países.

En segundo lugar, las páginas web de los distintos institutos de estadística oficiales de cada país proveen datos de valor agregado por sector, disponiendo de información para quince sectores:

1. Agricultura, ganadería, caza, silvicultura y pesca

2. Explotación de minas y canteras

3. Industrias manufactureras

4. Electricidad, gas y agua

5. Construcción

6. Comercio al por mayor y al por menor

7. Hoteles y restaurantes

8. Transporte y comunicaciones

9. Intermediación financiera

10. Actividades inmobiliarias, empresariales y de alquiler

11. Administración pública y defensa

12. Educación

13. Salud

14. Otras actividades de servicios comunitarios.

15. Servicio Doméstico

De las encuestas de hogares se obtienen los datos de salarios, edad, niveles de empleo y desempleo, género, nivel educativo, experiencia, intensidad de uso de cada tipo de

\footnotetext{
${ }^{4}$ Los países son: Argentina, Bolivia, Brasil, Chile, Colombia, Costa Rica, República Dominicana, Ecuador, Honduras, México, Panamá, Perú, Paraguay, El Salvador, Uruguay y Venezuela.
} 
trabajo por sector y región de residencia (necesarios para construir las primas salariales, la oferta y otros controles).

Por otro lado, se utilizan datos de términos de intercambio y Producto Bruto Interno per cápita de World Development Indicators (WDI) del Banco Mundial, y datos de salario mínimo de la Comisión Económica para América Latina y el Caribe (CEPAL). ${ }^{5}$

El estudio se enmarca en las contribuciones de Tinbergen (1975) sobre la "carrera entre educación y tecnología", quien postula que si bien el cambio tecnológico favorece la demanda relativa del trabajo calificado, aumentando la prima por educación $\mathrm{y}$, consecuentemente, la desigualdad, este efecto podría ser contrarrestado con un aumento del nivel educativo de la sociedad. Sin embargo, como se explica más adelante, este enfoque tiene el problema de que en la realidad no se puede identificar de manera precisa movimientos simultáneos de las curvas de oferta y demanda, dado que solo se observan los precios y las cantidades de equilibrio.

El marco teórico de este trabajo se basa también en los modelos de Goldin y Katz (2007) y Katz y Murphy (1992). El primer trabajo propone la utilización de una función de producción con elasticidad de sustitución constante (CES) que asume la existencia de dos factores de producción, correspondientes a dos niveles de calificación de los trabajadores (alta y baja). El segundo toma datos de primas salariales y oferta de trabajo calificado vs. no calificado y obtiene de manera residual la demanda relativa.

El modelo entonces asume una función de producción CES con dos factores de producción: trabajo calificado (S) y no calificado (U).

$$
Q_{t}=A_{t}\left[\lambda_{t} S_{t}^{\rho}+\left(1-\lambda_{t}\right) U_{t}^{\rho}\right]^{\frac{1}{\rho}}
$$

donde el producto total (Q) es una función de las cantidades de estos factores y los parámetros tecnológicos $\rho$ y $\lambda$, con una elasticidad de sustitución entre el trabajo calificado y no calificado de $\sigma_{S U}=(1-\rho)^{-1}$.

\footnotetext{
${ }^{5}$ Algunas pruebas de robustez incluyen datos de salario mínimo de ILOSTAT de la Organización Internacional del Trabajo, datos de desempleo de cuentas nacionales y datos de valor agregado por sector de la CEPAL.
} 
Bajo competencia perfecta, con una gran cantidad de firmas y factores que son remunerados según el valor de su producto marginal, la prima salarial entre $\mathrm{S}$ y $\mathrm{U}$ $\left(w_{S} / w_{U}\right)$ satisface que:

$$
\log \left(\frac{w_{S_{t}}}{w_{U_{t}}}\right)=\log \left(\frac{\lambda_{t}}{1-\lambda_{t}}\right)-\frac{1}{\sigma_{S U}} \log \left(\frac{S_{t}}{U_{t}}\right)
$$

Cuanto más alto el parámetro correspondiente a la elasticidad de sustitución $\left(\sigma_{S U}\right)$, más cerca están los dos tipos de trabajo a ser sustitutos perfectos, y por ende los salarios relativos no estarían correlacionados con las cantidades relativas de cada factor.

Como se menciona arriba, el problema del enfoque de Tinbergen es que en la realidad solo se observan precios y cantidades de equilibrio, y no es posible identificar movimientos simultáneos de las curvas de oferta y demanda. Siguiendo a Katz y Murphy (1992), se utilizan las primas salariales observadas y los cambios relativos en las cantidades de cada tipo de trabajo como medidas de precios relativos y de la oferta, y se computan los cambios en la demanda relativa de manera residual; es decir, para un determinado valor de elasticidad de sustitución, se computan las cantidades que serían compatibles con los cambios observados en los precios y la oferta. La demanda residual entonces tiene la siguiente forma:

$$
D(t)=\sigma \log \left(\frac{w_{S_{t}}}{w_{U_{t}}}\right)+\log \left(\frac{S_{t}}{U_{t}}\right)
$$

Las brechas salariales por nivel educativo $\left(\begin{array}{lll}w_{S_{t}} & \mathrm{y} w_{U_{t}}\end{array}\right)$ se construyen a partir de regresiones de Mincer que incluyen dummies por nivel educativo alcanzado ${ }^{6}$, por experiencia potencial $(0-15 ; 16-30 ; 30+)$, región de residencia y una variable dicotómica urbano/rural. La variable dependiente es el logaritmo del salario horario del individuo y las regresiones se realizan solo para hombres entre 25 y 64 años de edad. Se excluye del análisis a las mujeres, para evitar los problemas derivados de las decisiones de participación laboral femenina. A su vez, el rango etario seleccionado para el estudio permite mitigar la posibilidad de que la manera en que los individuos bajo análisis participan en el mercado laboral esté afectada por decisiones educativas o de retiro. Por

\footnotetext{
${ }^{6}$ Las dummies por nivel educativo son: superior completa (supc), superior incompleta (supi), secundaria completa (secc), secundaria incompleta (seci), primaria completa (pric) y la categoría omitida, primaria incompleta (prii).
} 
último, solo se tuvieron en cuenta a los individuos ocupados con salarios positivos y se eliminaron valores extremos. ${ }^{7}$

Con el objetivo de otorgarle una importancia más adecuada a las diferencias salariales entre diferentes categorías de trabajadores, se obtiene la proporción de trabajadores existentes en cada categoría respecto al total de trabajadores $(\gamma)$ para ponderar con ellos los coeficientes obtenidos en las regresiones de Mincer. Entonces el cómputo de las brechas salariales entre calificados y no calificados se realiza de la siguiente manera:

$$
\ln \left(\frac{w_{S}}{w_{U}}\right)=\beta_{\text {sup.c,i }}-\left[\gamma_{\text {sup. } i, i} \beta_{\text {sup. } i, i}+\gamma_{\text {sec. } ., i} \beta_{\text {sec.c. }, i}+\gamma_{\text {sec. } i, i} \beta_{\text {sec. } ., i}+\gamma_{\text {pri.c, }, i} \beta_{\text {pri.c, }, i}\right]
$$

En cuanto a la oferta relativa, se elaboraron dos medidas alternativas, siendo los resultados de este trabajo robustos a la utilización de cualquiera de ellas en el análisis. La primera medida consiste simplemente en contar el número de trabajadores en cada categoría por país y año. La alternativa utiliza las horas trabajadas reportadas por los individuos de cada categoría en cada país y año. ${ }^{8}$

\section{Estructura productiva}

Por último, y a los fines de identificar la relación entre los cambios en la participación de los sectores económicos y la desigualdad salarial, se computa un índice de estructura productiva. Dicho índice intenta cuantificar en qué medida el crecimiento diferencial de los sectores económicos puede afectar la demanda relativa del trabajo calificado vs. no calificado, en función de la intensidad de uso promedio de los mismos por las firmas del sector. A medida que algunos sectores de la economía ganan relevancia, esto debe ser a costa de la participación de otros. Si las intensidades de uso de los distintos factores de los sectores ganadores y perdedores fuesen exactamente las mismas, los efectos sobre los salarios serían mínimos o nulos ya que la economía puede ajustarse a la nueva coyuntura relocalizando recursos. Pero si este no fuese el caso, habría espacio para que este proceso conlleve a cambios distributivos.

Por ejemplo, analicemos el caso de un aumento en la participación en el valor agregado de un sector intensivo en trabajo calificado en desmedro de otro intensivo en trabajo no

\footnotetext{
${ }^{7}$ Se consideran como valores extremos a aquellos salarios menores al percentil 1 y mayores al percentil 99.

${ }^{8}$ Los resultados presentados en la sección 4 corresponden a la primera alternativa.
} 
calificado. Este último libera al mercado una mayor cantidad de trabajo no calificado que la que el sector que ha ganado importancia puede absorber. De esta manera, y suponiendo que no existe sustitución perfecta entre ambos tipos de trabajo, ocurre un exceso de oferta de trabajo no calificado que no es más que la contracara de un exceso de demanda de trabajo calificado. Ante este desequilibrio, el mercado tenderá a ajustar incrementando los pagos a trabajadores calificados y disminuyendo los de trabajadores no calificados; en consecuencia, aumenta la prima salarial por efecto del cambio en la participación relativa en el valor agregado de distintos sectores de la economía.

El presente trabajo propone un índice de estructura productiva con la siguiente forma:

$$
I_{i, t}=\sum_{j} \overline{\theta_{J, l}} * S_{j, i, t}
$$

donde $\overline{\theta_{J, l}}$ es la intensidad de uso del trabajo calificado (en particular, trabajadores con educación superior completa) promedio del sector j en el país i; es decir, la proporción de trabajo calificado sobre el total de trabajo en el sector. Dicho coeficiente permanece fijo para cada sector de cada país en todo el período. Por otro lado, $S_{j, i, t}$ es la participación del sector $\mathrm{j}$ en el valor agregado total del país $\mathrm{i}$ en el año t. En consecuencia, el índice de estructura productiva toma valores entre 0 y 100, siendo 0 en caso de que ningún sector utilizara trabajo calificado y 100 si todos los sectores utilizan solo trabajo calificado.

La lógica que se sigue en este trabajo consiste en tomar a los cambios en la estructura productiva como exógenos. Es decir, los cambios en la participación de los sectores económicos en el producto total se interpretan como cambios exógenos en la demanda relativa del trabajo calificado respecto al no calificado. Estos cambios beneficiarán a un tipo de trabajador o a otro de acuerdo a la intensidad de uso promedio de cada uno en las firmas ubicadas en sectores ganadores y perdedores. Finalmente, y mediante este canal, los cambios en la estructura productiva de los países afectan las primas salariales de calificados sobre no calificados.

Naturalmente, este tipo de análisis no está librado de potenciales problemas de endogeneidad. Pueden ocurrir shocks que afecten conjuntamente tanto a los salarios como a la estructura productiva, así como perturbaciones fuertes en los salarios que afecten diferencialmente a los sectores económicos, promoviendo cambios en sus 
participaciones en el producto. Otra fuente potencial de endogeneidad, tal como apuntan Atkinson y Bourguignon (2015), radica en la posibilidad de que no solo las primas salariales sean determinadas por la oferta relativa de diferentes tipos de empleo, sino que también ocurra el proceso inverso. Es decir, que los individuos observen las primas salariales existentes y a partir de ello decidan, por ejemplo, sus decisiones educativas. Sin embargo, las decisiones educativas toman tiempo en dar sus frutos, por lo que este tipo de reacciones solo se observarían en el largo plazo.

Es por estas razones que este trabajo no pretende identificar una relación causal entre cambios en la estructura productiva y desigualdad salarial, sino más bien busca ilustrar correlaciones entre estos fenómenos, que sugieran algún canal causal, que pueda ser estudiado por otras estrategias de identificación.

Con la metodología de Katz y Murphy (1992) y siguiendo a Manacorda et al. (2010) y a Galiani et al. (2017), se utiliza un panel de datos a nivel país-año y se realizan regresiones de la prima salarial de calificados sobre no calificados como función de la oferta relativa de cada tipo de factor, del índice de estructura productiva y de otros controles, siguiendo una ecuación con la forma:

$$
\log \left(\frac{w_{S}}{w_{U}}\right)_{i, t}=\alpha+\beta_{1} \log \left(\frac{\mathrm{S}}{\mathrm{U}}\right)_{\mathrm{i}, \mathrm{t}}+\beta_{2} \log \left(I_{i, t}\right)+\mathrm{X}_{\mathrm{i}, \mathrm{t}}+\mathrm{P}_{i}+T_{t}+\varepsilon_{i, t}
$$

donde el lado izquierdo de la ecuación es el logaritmo de la prima salarial en el país i en el año $\mathrm{t}\left(\left(\frac{w_{S}}{w_{U}}\right)_{i, t}\right)$, y del lado derecho se tiene una constante, el logaritmo de la oferta relativa del trabajo calificado $\left(\left(\frac{\mathrm{S}}{\mathrm{U}}\right)_{i, t}\right)$, el logaritmo del índice de estructura productiva $\left(I_{i, t}\right)$, otros controles $\left(\mathrm{X}_{\mathrm{i}, \mathrm{t}}\right)$ y efectos fijos por país $\left(\mathrm{P}_{i}\right)$ y año $\left(T_{t}\right)$.

Cabe aclarar que los resultados deberían interpretarse como estimaciones reducidas de los promedios (no ponderados) para toda la región, teniendo en cuenta que esto no necesariamente representa las experiencias de cada uno de los dieciséis países. A su vez, la inclusión de efectos fijos a nivel país y año intenta capturar los factores de demanda que van más allá de la estructura productiva y de los demás controles incluidos. En particular, los efectos fijos por país son capaces de capturar particularidades propias de cada país de escasa variación en el tiempo, mientras que la inclusión de efectos fijos por 
año tiene como objetivo captar tendencias temporales que puedan afectar a las primas salariales.

\section{Resultados}

En esta sección se discuten los principales resultados del trabajo, con el objetivo de ilustrar la relación existente entre la estructura productiva medida por el índice construido y las primas por educación.

Como primer paso, se evalúa la evolución a lo largo del tiempo de las primas salariales promedio para América Latina entre trabajadores calificados y no calificados y su oferta y demanda relativas.

\section{Figura 4.}

\section{Prima salarial, oferta y demanda relativas.}

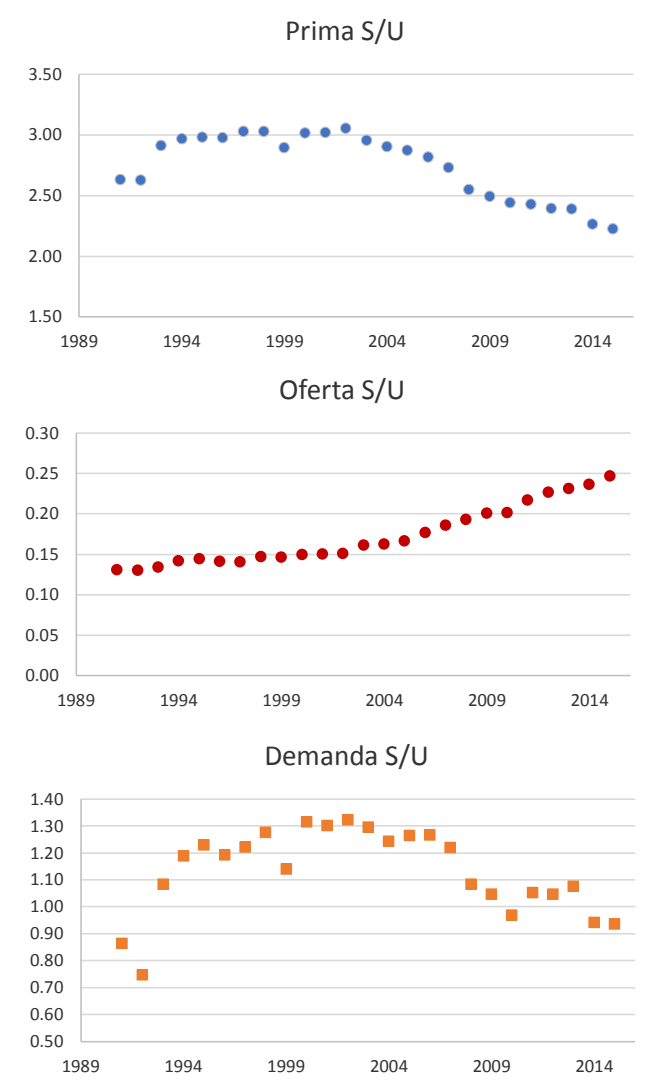

Fuente: elaboración propia en base a SEDLAC (CEDLAS y Banco Mundial).

Nota: para calcular la demanda relativa se supone una elasticidad de sustitución de 3. A fines ilustrativos y para obtener una muestra balanceada, se reemplazan observaciones atípicas y faltantes por el promedio de las más cercanas, y se eliminan los países con muy pocas observaciones o que no siguen la tendencia de la región (Colombia, Costa Rica, Honduras, Ecuador, El Salvador y Venezuela). 
La Figura 4 indica que en la década de los noventa, y a pesar de que la oferta relativa de trabajo calificado se incrementó, existió un aumento en las primas salariales de los calificados por sobre los no calificados. Esto lleva a pensar que hay factores que aumentaron la demanda relativa del trabajo calificado más allá del aumento en su oferta relativa análoga. Luego, en la primera década del nuevo siglo, las diferencias salariales por nivel educativo se redujeron, en parte por un aumento en la oferta relativa de trabajo calificado. Para una elasticidad de sustitución de 3 (consistente con la utilizada en Galiani et al. 2017), los patrones de las primas salariales y las ofertas relativas en los dos mil son consistentes con una disminución de la demanda relativa de trabajo calificado. En contraste, en la década actual la reducción en las primas perdió ritmo e incluso comienzan a verse algunos signos de reversión de esta tendencia a la baja en algunos países. En definitiva y teniendo en cuenta que la oferta relativa de trabajo calificado se ha incrementado constantemente desde 1991, como indica la Figura 4, la dinámica de la desigualdad salarial por nivel educativo se encuentra bastante ligada a la evolución de la demanda relativa entre trabajo calificado y no calificado. Si bien durante todo el periodo existió una presión hacia abajo en las primas salariales por educación producto de mayores niveles educativos alcanzados por la población, la evolución de la demanda relativa estimada de manera residual es consistente con un incremento en dicha dispersión salarial durante los noventa, que tiende a caer a principios del nuevo milenio para luego estancarse a partir de 2010.

La Figura 5 ilustra el mismo concepto que la anterior, pero esta vez para la muestra completa y redefiniendo los tres subperíodos (1990s, 2000s y 2010s) de manera diferente para cada país. Nuevamente se computa la demanda utilizando una elasticidad de sustitución entre trabajadores calificados y no calificados de 3. No obstante, también se muestran como alternativas los casos en que dicha elasticidad toma valores de 2 y 4 , obteniéndose resultados en el mismo sentido. 


\section{Figura 5.}

\section{Prima salarial, Oferta y Demanda relativas.}

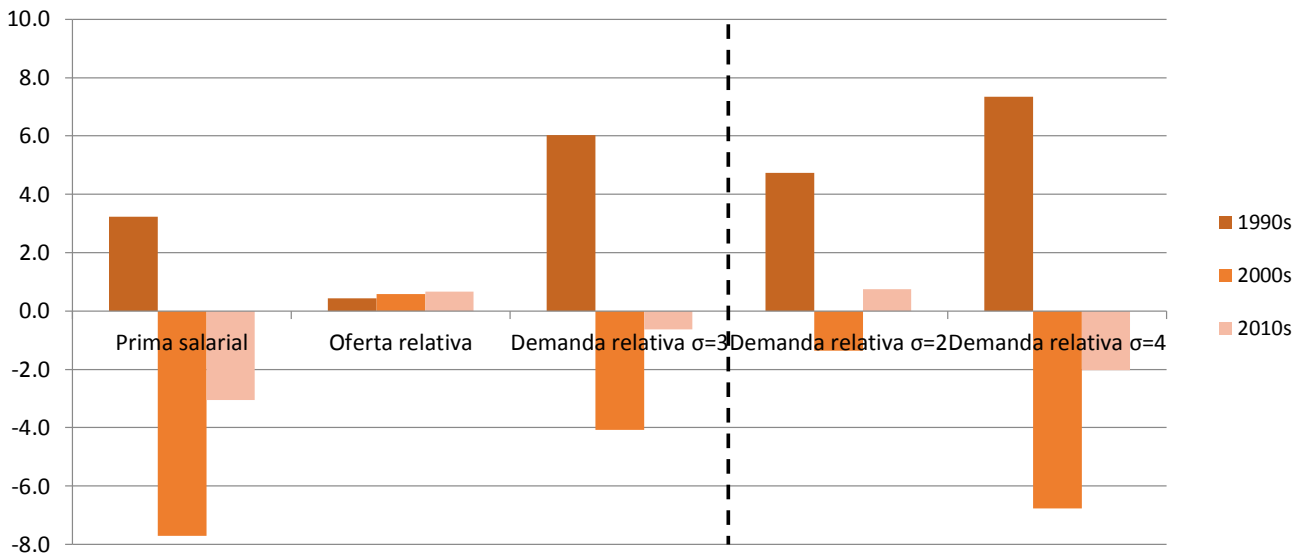

Fuente: elaboración propia en base a SEDLAC (CEDLAS y Banco Mundial).

Nota: los años utilizados para cada país son: Argentina 1992, 2000, 2009, 2014; Bolivia 2001, 2009, 2015; Brasil 1993, 2002, 2009, 2015; Chile 1991, 2000, 2006, 2015; Colombia 1996, 2001, 2008, 2015; Costa Rica 1992, 2002, 2008, 2015; Rep. Dominicana 1996, 2000, 2010, 2015; Ecuador 2003, 2009, 2014; El Salvador 1995, 2002, 2009, 2015; Honduras 1993, 2003, 2009, 2015; México 1992, 2000, 2008, 2011; Nicaragua 1993, 2001, 2009, 2015; Panamá 1992, 2002, 2009, 2015; Paraguay 1995, 2003, 2009, 2015; Perú 1997, 2002, 2009, 2015; Uruguay 1992, 2002, 2009, 2012; y Venezuela 1995, 2002, 2008, 2012.

En dicha figura se observa cómo los cambios promedio en la oferta son muy pequeños, y parece que la dinámica de las primas salariales se asocia en mayor medida con cambios en la demanda relativa de trabajo calificado respecto al no calificado, independientemente de la elasticidad de sustitución que se utilice.

\section{Primas salariales y estructura productiva}

Una vez conocidas las dinámicas de la prima salarial, oferta y demanda relativas entre trabajadores calificados y no calificados, se analiza la posible relación existente entre las mismas y la estructura productiva, medida por el índice mencionado anteriormente. En particular, el cambio en la estructura productiva es uno de los factores que explican la demanda relativa de trabajo calificado. En el siguiente gráfico se expresa la evolución conjunta del índice de estructura productiva y las primas salariales entre trabajadores calificados y no calificados. 


\section{Figura 6.}

\section{Índice de estructura productiva y primas salariales por calificación.}

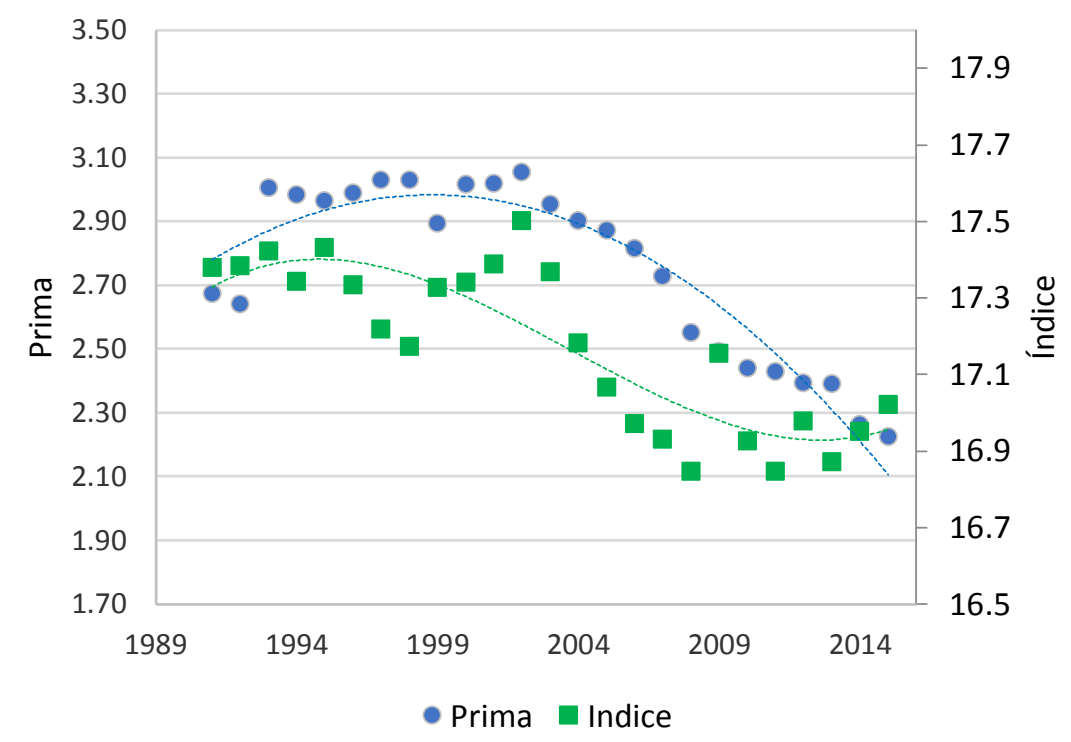

Fuente: elaboración propia en base a cuentas nacionales, SEDLAC (CEDLAS y Banco Mundial).

Nota: a fines ilustrativos y para obtener una muestra balanceada, se reemplazan observaciones atípicas y faltantes por el promedio de las más cercanas, y se eliminan los países con muy pocas observaciones o que no siguen la tendencia de la región (Colombia, Costa Rica, Honduras, Ecuador, El Salvador y Venezuela).

De la Figura 6 se desprende que, incluso sin controlar por otros factores que pueden afectar la relación entre ambas variables, la dinámica de la prima salarial entre trabajadores calificados y no calificados posee ciertas similitudes con la del índice de estructura productiva. El crecimiento en el índice de fines de los noventa se ve acompañado por un crecimiento en la prima, seguido de una caída fuerte en ambas series a partir de 2002, y un cierto estancamiento en la nueva década. De esta manera, puede pensarse que la estructura productiva podría ser uno de los factores de demanda que afectan las primas salariales por educación.

Adicionalmente, es interesante ver dentro de cada país la evolución conjunta de la prima salarial entre trabajadores calificados y no calificados y el índice. 


\section{Figura 7.}

\section{Evolución conjunta por país de la prima salarial entre calificados y no calificados y}

el índice de estructura productiva.

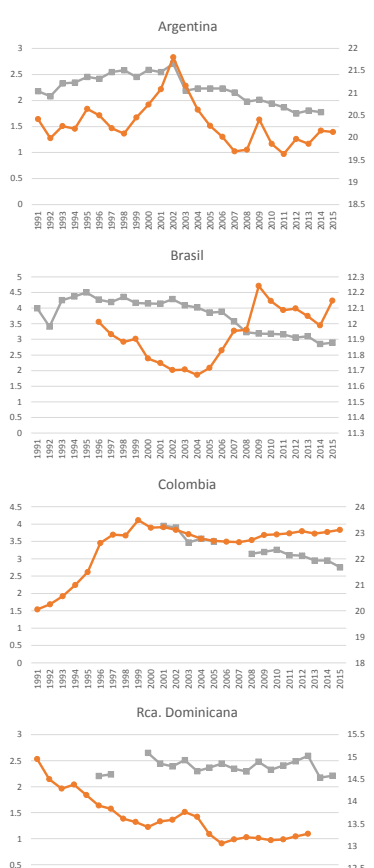

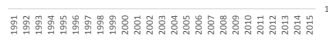

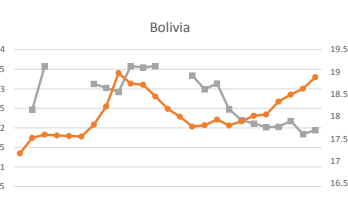

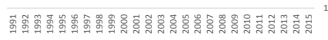

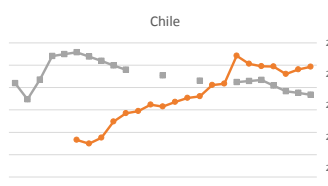

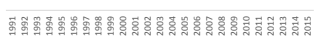
costa Rica

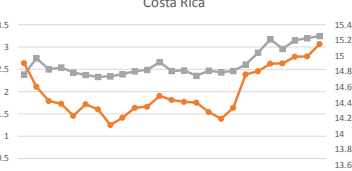

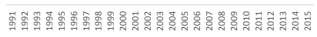

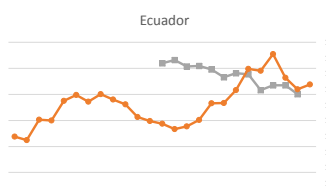

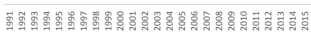
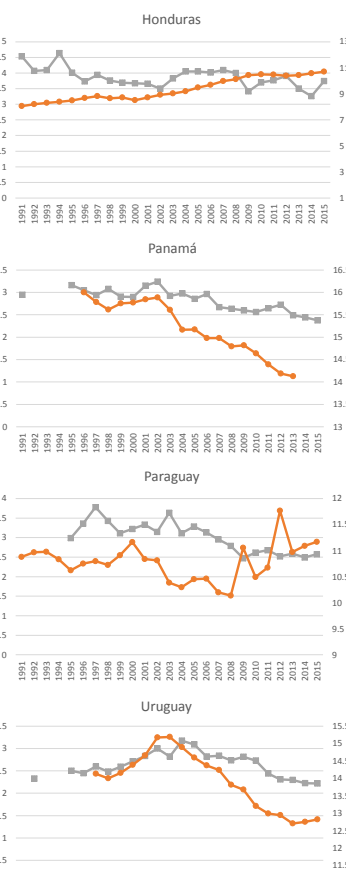

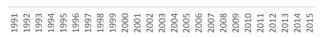

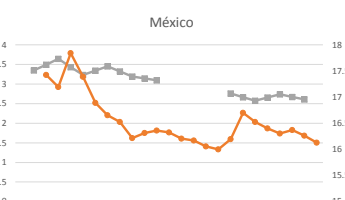

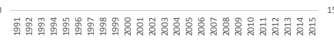
Perú

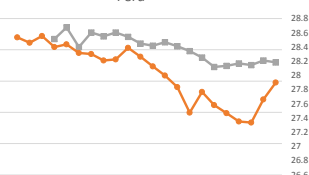

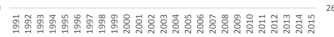

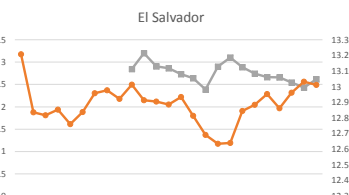

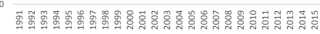

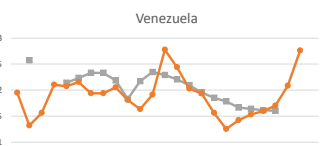

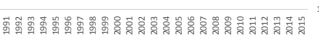

Fuente: elaboración propia en base a datos de cuentas nacionales y SEDLAC (CEDLAS y Banco Mundial).

Nota: la línea gris con cuadrados corresponde a la prima S/U (eje izquierdo), mientras que la naranja con círculos es el índice de estructura productiva (eje derecho).

Los gráficos de la Figura 7 muestran que la relación entre estas variables no se limita al promedio de América Latina, sino que también se observa en cierta medida en la mayoría de los países. Naturalmente, no podría esperarse que ambas series varíen conjuntamente en todo momento debido a que la estructura productiva no es el único determinante posible de las primas salariales. Sin embargo, y a pesar de la heterogeneidad existente en la evolución de la dispersión salarial entre países, en general el índice de estructura productiva acompaña a la evolución de la desigualdad salarial, por lo que podría esperarse que la estructura productiva explique parte de la variación de las primas salariales. Solamente en años puntuales, mayormente concordantes con crisis económicas, ambas medidas presentan diferente evolución.

La Tabla 1 (en el Apéndice) presenta un análisis de regresión tendiente a identificar en qué medida el cambio en la estructura productiva de los países latinoamericanos se 
correlaciona con la dinámica de las primas salariales por nivel educativo. ${ }^{9}$ Cabe recordar la necesidad de ser prudentes respecto a la interpretación de los resultados obtenidos; solo se encuentran correlaciones y no es posible hablar de relación causal con certeza.

A lo largo de las especificaciones (1) a (12) se fueron agregando efectos fijos por país y año y otras variables de control. Las especificaciones (13) a (16) corresponden a una submuestra en la que se eliminan las observaciones que producen saltos inusuales en las series, que generalmente se asocian a crisis económicas particulares de los distintos países.

Analizando los resultados expuestos en la Tabla 1, en primer lugar se puede observar cómo el aumento en la educación, reflejado por incrementos en la oferta relativa de trabajadores calificados, tiende a disminuir las primas salariales entre calificados y no calificados. Esta relación resulta negativa y significativa para todas las especificaciones analizadas e incluso su coeficiente se mantiene estable cuando se controla por diversos factores ligados a la demanda. Sin embargo, la magnitud del coeficiente es bastante menor a la que obtienen Galiani et al (2017) (0.16 vs. 0.4 que obtienen los autores, en promedio).

Cabe destacar la importancia de controlar por efectos fijos a nivel país y año, ya que al tenerlos en cuenta se incrementa el R-cuadrado de las estimaciones. La inclusión de dichos efectos fijos permite identificar, al menos en parte, factores ligados a la demanda que pueden afectar a las primas salariales. En particular, los efectos fijos por país son capaces de captar todos aquellos factores específicos de cada país e invariantes en el tiempo que pueden afectar la variable dependiente, mientras que los efectos fijos por año tienen en cuenta posibles tendencias temporales en las series incluidas en el análisis.

Naturalmente, existen razones teóricas para pensar en otros componentes que afectan la demanda relativa de trabajadores calificados. En particular, se enfoca el análisis al cambio en la estructura productiva de un país como un posible factor de demanda que se relaciona con la evolución de las primas salariales.

Los resultados sugieren que el cambio en la estructura productiva, reflejado en las variaciones del índice descripto en la sección anterior, representa un factor relevante a la

\footnotetext{
${ }^{9}$ Dicha tabla presenta las especificaciones que consideran la oferta relativa de trabajo calificado en número de empleados. Aquellas que miden dicha oferta en términos de horas trabajadas arrojan resultados similares.
} 
hora de explicar las dinámicas de las primas salariales entre trabajadores calificados y no calificados. En efecto, a lo largo de prácticamente todas las especificaciones de la Tabla 1, dicha variable presenta correlaciones positivas y significativas con la dispersión salarial. A su vez, la magnitud del coeficiente es robusta a la inclusión de controles adicionales, tomando valores de entre 0.7 y 0.9 . En definitiva, la Tabla 1 sugiere que existe una correlación positiva, significativa y robusta entre el índice de estructura productiva construido y las primas salariales entre trabajadores calificados y no calificados. ${ }^{10}$

Para tener una idea de lo que implica dicha magnitud, tomemos por ejemplo un incremento del $1 \%$ en el índice de estructura productiva (que es lo que efectivamente ocurrió en promedio para América Latina en el período 1996-2002), producido por un aumento en la participación en el valor agregado de sectores más intensivos en trabajo calificado. Esto implica, basándonos en los coeficientes que arrojan las estimaciones presentadas en la Tabla 1, que las primas salariales de los trabajadores calificados respecto a los no calificados aumentarían en promedio y manteniendo todo lo demás constante en un $0.8 \%$.

En el período 2002-2008, por otro lado, el cambio en la estructura productiva de los países latinoamericanos implicó una disminución en el índice de estructura productiva de alrededor de $3.7 \%$, lo que se asociaría, de acuerdo a las estimaciones presentadas, a una reducción de la prima de casi 3\%. Por último, el índice vuelve a aumentar en el último período (1\%), lo que estaría asociado a un aumento de las primas de un $0.8 \%$. Es decir que, en principio, los resultados sugieren que las variaciones en la estructura productiva de los países latinoamericanos podrían ser uno de los factores detrás del recientemente estudiado fenómeno de desaceleración de la caída de la desigualdad en América Latina.

Adicionalmente al índice de estructura productiva, las estimaciones presentadas en la Tabla 1 presentan controles por otros factores que la literatura asocia a la demanda relativa de trabajadores calificados vs. no calificados.

\footnotetext{
10 Como prueba de robustez, se realiza el mismo ejercicio pero usando como fuente alternativa datos de valor agregado por sector de la CEPAL en lugar de cuentas nacionales, con una menor desagregación (9 sectores en vez de 16), obteniendo un coeficiente similar al presentado en la Tabla 1.
} 
Relacionado al comercio internacional se incluye el logaritmo de un índice de términos de intercambio como un posible factor de demanda. ${ }^{11}$ Durante la década de los dos mil la mayoría de los países de la región experimentaron una fuerte mejora en sus términos de intercambio. En todas las especificaciones presentadas se encuentra un signo negativo y significativo: mayores términos de intercambio se relacionan con caídas en las primas salariales de calificados sobre no calificados. Este resultado indica que, en principio, mejoras en las condiciones del comercio internacional generan, en términos relativos, mayor demanda de trabajadores no calificados. Esto es coherente con lo mencionado en la introducción, donde se aclara que en todos los países los cuatro sectores más intensivos en trabajo calificado eran Intermediación Financiera, Actividades inmobiliarias, empresariales y de alquiler, Educación y Salud, mientras que el quinto puesto era ocupado en once de los dieciséis países por Administración pública y defensa.

Este resultado para los términos de intercambio es compatible con literatura previa para América Latina (Galiani et al., 2011), aunque no puede establecerse una relación causal dado que existen muchos canales difícilmente separables bajo los cuales los términos de intercambio pueden afectar las primas por calificación.

Otro factor relevante a la hora de analizar los posibles determinantes de las primas salariales por nivel educativo es el grado de desarrollo del país, medido mediante su Producto Bruto Interno per cápita. Los resultados indican la existencia de una relación negativa entre el producto per cápita de los países y su dispersión de ingresos salariales. A medida que los países se desarrollan ven caer sus niveles de desigualdad salarial, pero esta disminución es cada vez menor, dado que el coeficiente del logaritmo del PBI al cuadrado es positivo y significativo al $1 \%$ para prácticamente todas las especificaciones.

Por otro lado, la literatura identifica factores cíclicos del mercado laboral que pueden afectar a las primas salariales por calificación. Por esta razón, se introducen como controles diversas tasas de desempleo, calculadas siguiendo el procedimiento de SEDLAC. Se controla por desempleo total, desempleo de hombres, y desempleo de cada tipo de trabajadores (Baja, Media y Alta educación). ${ }^{12}$ Sin embargo, en la mayoría

\footnotetext{
${ }^{11}$ El índice de términos de intercambio se calcula como el ratio porcentual de índices de valor unitario de exportaciones sobre índices de valor unitario de importaciones, tomando como año base el 2000. Fuente: WDI del Banco Mundial.

${ }^{12}$ Los resultados no cambian de manera significativa cuando se incluyen tasas de desempleo de cuentas nacionales, tanto de la población total como de los hombres.
} 
de las especificaciones el coeficiente es no significativo, aunque sí es negativo y significativo al $10 \%$ para las tasas de desempleo de gente de calificación media en algunas especificaciones.

Al incluir controles por salario mínimo se encuentra una relación negativa, significativa y robusta entre esta variable y las primas salariales entre calificados y no calificados, tanto utilizando datos de la CEPAL como de ILOSTAT. Por lo tanto, existe evidencia preliminar que permite afirmar que las políticas de salario mínimo tienden a disminuir la dispersión salarial en el mercado laboral.

Por último, en las especificaciones que contienen una submuestra que quita aquellos países y años que tienen saltos atípicos tanto en el indicador de estructura productiva como en sus primas salariales, se mantienen el signo y la significatividad de los coeficientes. Lo que es más, para el caso particular del índice de estructura productiva el coeficiente aumenta su magnitud respecto a la especificación análoga con la muestra completa entre un 13 y un $20 \%$.

\section{Conclusiones}

Este trabajo estudia los determinantes de las primas salariales entre trabajadores de alta calificación y trabajadores de calificación media y baja para dieciséis países de América Latina en el período 1991-2015. En particular, el interés central está en identificar elementos de la demanda relativa asociados a la estructura productiva de un país en un año determinado. Se construye un índice de estructura productiva a partir de la participación en el valor agregado de quince sectores económicos ponderada por la participación promedio para todos los años del trabajo calificado en cada uno de ellos para cada país, y se encuentra que aumentos en dicho índice están asociados a aumentos en las primas salariales de los trabajadores calificados sobre los no calificados de manera significativa. Es decir, cuando se produce algún shock exógeno en la economía que lleva a un crecimiento en la participación de los sectores que más utilizan trabajo calificado en desmedro de la participación de otros que lo utilizan en menor medida, aumentan las primas salariales de calificados sobre no calificados. Esto concuerda con la literatura existente sobre la importancia de los factores de demanda para explicar la dinámica de las brechas salariales por educación, en particular entre trabajadores con nivel terciario completo o más y el resto. Sin embargo, existen numerosos elementos de 
la demanda que no son estudiados en profundidad en este trabajo y sobre los cuales se debería apuntar en futuras investigaciones. 


\section{Referencias}

Atkinson, Anthony B. y Bourguignon, François (Eds.). 2015. Handbook of Income Distribution. Volume 2. Elsevier.

Buera, Francisco J., Kaboski, Joseph P. y Rogerson, Richard. 2015. "Skill Biased Structural Change," Working Paper 21165, National Bureau of Economic Research.

Fernández, Manuel. y Messina, Julián. 2017. "Skill premium, labor supply and changes in the structure of wages in Latin America". IDB Working Paper Series 786.

Galiani, Sebastian, Cruces, Guillermo, Acosta, Pablo y Gasparini, Leonardo. 2011. "Educational Upgrading and Returns to Skills in Latin America: Evidence from a SupplyDemand Framework, 1990-2010”. World Bank Policy Research Paper 5921.

Galiani, Sebastian, Cruces, Guillermo, Acosta, Pablo y Gasparini, Leonardo. 2017. "Educational Upgrading and Returns to Skills in Latin America: Evidence from a Supply-Demand Framework". Working Paper 24015, National Bureau of Economic Research.

Gasparini, Leonardo, Cruces, Guillermo y Tornarolli, Leopoldo. 2011. "Recent Trends in Income Inequality in Latin America". Economia 10, 147-201.

Gasparini, Leonardo, Cruces, Guillermo y Tornarolli, Leopoldo. 2016. "Chronicle of a Deceleration Foretold: Income Inequality in Latin America in the 2010s". Revista de Economía Mundial 43, 25-46.

Goldin, Claudia y Katz, Lawrence F. 2007. "The Race Between Education and Technology: The Evolution of U.S. Educational Wage Differentials, 1890 to 2005". Working Paper 12984, National Bureau of Economic Research.

Gustafsson, Björn y Johansson, Mats. 1999. "In Search of Smoking Guns: What Makes Income Inequality Vary over Time in Different Countries?". American Sociological Review Vol. 64, No. 4 (Aug., 1999), pp. 585-605

Katz, Lawrence F. y Murphy, Kevin M. 1992. "Changes in Relative Wages, 1963-1987: Supply and Demand Factors". Quarterly Journal of Economics 107, 35-78.

Manacorda, Marco, Sánchez-Páramo, Carolina y Schady, Norbert. 2010. "Changes in Returns to Education in Latin America: The Role of Demand and Supply of Skills". Industrial and Labor Relations Review 63, 307-326.

Martorano, Bruno y Sanfilippo, Marco. 2014. "Structural change and wage inequality in the manufacturing sector: long run evidence from East Asia". Documento de trabajo N. 09/2014. DISEI - Università degli Studi di Firenze 
Rendall, Michelle. 2013. "Structural Change in Developing Countries: Has it Decreased Gender Inequality?". World Development. Vol: 45, Page: 1-16

Rodrik, Dani y McMillan, Margaret S. 2011. "Globalization, Structural Change and Productivity Growth". En Making Globalization Socially Sustainable, editado por Mark Bachetta y Marion Jansen. International Labor Organization, Geneva Switzerland.

Tinbergen, Jan. 1975. Income Distribution: Analysis and Policies. North-Holland: Amsterdam. 


\section{Apéndice}

\section{Tabla 1. Correlaciones con la prima salarial entre calificados y no calificados.}

\begin{tabular}{|c|c|c|c|c|c|c|c|c|c|c|c|c|c|c|c|c|}
\hline Variables & $\begin{array}{c}(1) \\
\text { Prima S/U }\end{array}$ & $\begin{array}{c}\text { (2) } \\
\text { Prima S/U }\end{array}$ & $\begin{array}{c}\text { (3) } \\
\text { Prima S/U }\end{array}$ & $\begin{array}{c}\text { (4) } \\
\text { Prima S/U }\end{array}$ & $\begin{array}{c}\text { (5) } \\
\text { Prima S/U }\end{array}$ & $\begin{array}{c}\text { (6) } \\
\text { Prima S/U }\end{array}$ & $\begin{array}{c}(7) \\
\text { Prima S/U }\end{array}$ & $\begin{array}{c}\text { (8) } \\
\text { Prima S/U }\end{array}$ & $\begin{array}{c}(9) \\
\text { Prima S/U }\end{array}$ & $\begin{array}{c}(10) \\
\text { Prima S/U }\end{array}$ & $\begin{array}{c}(11) \\
\text { Prima S/U }\end{array}$ & $\begin{array}{c}(12) \\
\text { Prima S/U }\end{array}$ & $\begin{array}{c}(13) \\
\text { Sin obs. } \\
\text { raras }\end{array}$ & $\begin{array}{c}(14) \\
\text { Sin obs. } \\
\text { raras }\end{array}$ & $\begin{array}{c}(15) \\
\text { Sin obs. } \\
\text { raras }\end{array}$ & $\begin{array}{c}(16) \\
\text { Sin obs. } \\
\text { raras }\end{array}$ \\
\hline Log (Oferta S/U) & $\begin{array}{c}-0.340 * * * \\
{[0.019]}\end{array}$ & $\begin{array}{c}-0.325 * * * \\
{[0.030]}\end{array}$ & $\begin{array}{c}-0.307^{* * *} \\
{[0.024]}\end{array}$ & $\begin{array}{c}-0.205^{* * *} \\
{[0.037]}\end{array}$ & $\begin{array}{c}-0.164 * * * \\
{[0.033]}\end{array}$ & $\begin{array}{c}-0.162^{* * *} \\
{[0.033]}\end{array}$ & $\begin{array}{c}-0.162^{* * *} \\
{[0.033]}\end{array}$ & $\begin{array}{c}-0.152^{* * *} \\
{[0.034]}\end{array}$ & $\begin{array}{c}-0.171^{* * *} \\
{[0.033]}\end{array}$ & $\begin{array}{c}-0.179 * * * \\
{[0.033]}\end{array}$ & $\begin{array}{c}-0.145^{* * *} \\
{[0.032]}\end{array}$ & $\begin{array}{c}-0.145^{* * *} \\
{[0.031]}\end{array}$ & $\begin{array}{c}-0.176^{* * *} \\
{[0.033]}\end{array}$ & $\begin{array}{c}-0.179^{* * *} \\
{[0.032]}\end{array}$ & $\begin{array}{c}-0.144^{* * *} \\
{[0.031]}\end{array}$ & $\begin{array}{c}-0.141^{* * *} \\
{[0.030]}\end{array}$ \\
\hline Log (Índice de EP) & & $\begin{array}{c}-0.034 \\
{[0.049]}\end{array}$ & $\begin{array}{c}0.440 * * * \\
{[0.157]}\end{array}$ & $\begin{array}{c}0.413^{* * *} \\
{[0.156]}\end{array}$ & $\begin{array}{c}0.736^{* * *} \\
{[0.187]}\end{array}$ & $\begin{array}{c}0.751^{* * *} \\
{[0.190]}\end{array}$ & $\begin{array}{c}0.744^{* * *} \\
{[0.189]}\end{array}$ & $\begin{array}{c}0.815^{* * *} \\
{[0.193]}\end{array}$ & $\begin{array}{c}0.796^{* * *} \\
{[0.189]}\end{array}$ & $\begin{array}{c}0.738^{* * *} \\
{[0.185]}\end{array}$ & $\begin{array}{c}0.687^{* * *} \\
{[0.196]}\end{array}$ & $\begin{array}{c}0.680 * * * \\
{[0.184]}\end{array}$ & $\begin{array}{c}0.900 * * * \\
{[0.193]}\end{array}$ & $\begin{array}{c}0.875^{* * *} \\
{[0.189]}\end{array}$ & $\begin{array}{c}0.792^{* * *} \\
{[0.197]}\end{array}$ & $\begin{array}{c}0.818^{* * *} \\
{[0.186]}\end{array}$ \\
\hline Log(Términos de Intercambio) & & & & & $\begin{array}{c}-0.205^{* * *} \\
{[0.028]}\end{array}$ & $\begin{array}{c}-0.208^{* * *} \\
{[0.029]}\end{array}$ & $\begin{array}{c}-0.207 * * * \\
{[0.029]}\end{array}$ & $\begin{array}{c}-0.207^{* * *} \\
{[0.029]}\end{array}$ & $\begin{array}{c}-0.236 * * * \\
{[0.030]}\end{array}$ & $\begin{array}{c}-0.235^{* * *} \\
{[0.030]}\end{array}$ & $\begin{array}{c}-0.174 * * * \\
{[0.027]}\end{array}$ & $\begin{array}{c}-0.172 * * * \\
{[0.026]}\end{array}$ & $\begin{array}{c}-0.237^{* * *} \\
{[0.030]}\end{array}$ & $\begin{array}{c}-0.237^{* * *} \\
{[0.030]}\end{array}$ & $\begin{array}{c}-0.184^{* * *} \\
{[0.027]}\end{array}$ & $\begin{array}{c}-0.184^{* * *} \\
{[0.026]}\end{array}$ \\
\hline Log (PBI pc PPP11) & & & & & $\begin{array}{c}-3.186 * * * \\
{[0.960]}\end{array}$ & $\begin{array}{c}-3.296 * * * \\
{[0.983]}\end{array}$ & $\begin{array}{c}-3.252^{* * *} \\
{[0.980]}\end{array}$ & $\begin{array}{c}-3.905 * * * \\
{[1.047]}\end{array}$ & $\begin{array}{c}-3.854 * * * \\
{[1.043]}\end{array}$ & $\begin{array}{c}-3.393 * * * \\
{[0.981]}\end{array}$ & $\begin{array}{c}-2.155^{* *} \\
{[1.018]}\end{array}$ & $\begin{array}{c}-2.508 * * * \\
{[0.952]}\end{array}$ & $\begin{array}{c}-3.457^{* * *} \\
{[1.077]}\end{array}$ & $\begin{array}{c}-3.262^{* * *} \\
{[1.003]}\end{array}$ & $\begin{array}{c}-2.137^{* *} \\
{[1.003]}\end{array}$ & $\begin{array}{c}-2.758^{* * *} \\
{[0.933]}\end{array}$ \\
\hline $\log (P B \mid p c P P P 11)^{\wedge} 2$ & & & & & $\begin{array}{c}0.184^{* * *} \\
{[0.052]}\end{array}$ & $\begin{array}{c}0.190^{* * *} \\
{[0.053]}\end{array}$ & $\begin{array}{c}0.188^{* * *} \\
{[0.053]}\end{array}$ & $\begin{array}{c}0.222^{* * *} \\
{[0.056]}\end{array}$ & $\begin{array}{c}0.220^{* * *} \\
{[0.056]}\end{array}$ & $\begin{array}{c}0.196 * * * \\
{[0.053]}\end{array}$ & $\begin{array}{l}0.124^{* *} \\
{[0.055]}\end{array}$ & $\begin{array}{c}0.143^{* * *} \\
{[0.052]}\end{array}$ & $\begin{array}{c}0.199 * * * \\
{[0.057]}\end{array}$ & $\begin{array}{c}0.189 * * * \\
{[0.054]}\end{array}$ & $\begin{array}{l}0.123^{* *} \\
{[0.054]}\end{array}$ & $\begin{array}{c}0.156 * * * \\
{[0.051]}\end{array}$ \\
\hline Desempleo Calif. Baja & & & & & & & & $\begin{array}{c}0.009 \\
{[0.006]}\end{array}$ & $\begin{array}{c}0.006 \\
{[0.006]}\end{array}$ & & $\begin{array}{c}-0.001 \\
{[0.005]}\end{array}$ & & $\begin{array}{c}0.002 \\
{[0.006]}\end{array}$ & & $\begin{array}{c}-0.005 \\
{[0.005]}\end{array}$ & \\
\hline Desempleo Calif. Media & & & & & & & & $\begin{array}{l}-0.011^{*} \\
{[0.006]}\end{array}$ & $\begin{array}{l}-0.008 \\
{[0.006]}\end{array}$ & & $\begin{array}{l}-0.000 \\
{[0.007]}\end{array}$ & & $\begin{array}{l}-0.004 \\
{[0.006]}\end{array}$ & & $\begin{array}{c}0.004 \\
{[0.007]}\end{array}$ & \\
\hline Desempleo Calif. Alta & & & & & & & & $\begin{array}{c}0.002 \\
{[0.005]}\end{array}$ & $\begin{array}{c}0.002 \\
{[0.005]}\end{array}$ & & $\begin{array}{c}0.004 \\
{[0.005]}\end{array}$ & & $\begin{array}{c}0.002 \\
{[0.005]}\end{array}$ & & $\begin{array}{c}0.004 \\
{[0.005]}\end{array}$ & \\
\hline Desempleo Total & & & & & & $\begin{array}{c}-0.001 \\
{[0.002]}\end{array}$ & & & & & & & & & & \\
\hline Desempleo Hombres & & & & & & & $\begin{array}{c}-0.001 \\
{[0.002]}\end{array}$ & & & $\begin{array}{c}-0.002 \\
{[0.002]}\end{array}$ & & $\begin{array}{c}0.005 \\
{[0.004]}\end{array}$ & & $\begin{array}{c}-0.002 \\
{[0.002]}\end{array}$ & & $\begin{array}{c}0.004 \\
{[0.004]}\end{array}$ \\
\hline Salario mínimo (CEPAL) & & & & & & & & & $\begin{array}{c}-0.041^{* * *} \\
{[0.013]}\end{array}$ & $\begin{array}{c}-0.043^{* * *} \\
{[0.013]}\end{array}$ & & & $\begin{array}{c}-0.040 * * * \\
{[0.012]}\end{array}$ & $\begin{array}{c}-0.041^{* * *} \\
{[0.012]}\end{array}$ & & \\
\hline Salario mínimo (ILOSTAT) & & & & & & & & & & & $\begin{array}{c}-0.055^{* * *} \\
{[0.009]}\end{array}$ & $\begin{array}{c}-0.051^{* * *} \\
{[0.009]}\end{array}$ & & & $\begin{array}{c}-0.055^{* * *} \\
{[0.009]}\end{array}$ & $\begin{array}{c}-0.050^{* * *} \\
{[0.009]}\end{array}$ \\
\hline Constante & $\begin{array}{c}0.337^{* * *} \\
{[0.038]}\end{array}$ & $\begin{array}{l}0.460^{* *} \\
{[0.183]}\end{array}$ & $\begin{array}{l}-0.982^{* *} \\
{[0.478]}\end{array}$ & $\begin{array}{l}-0.822^{*} \\
{[0.475]}\end{array}$ & $\begin{array}{c}12.851^{* * *} \\
{[4.242]}\end{array}$ & $\begin{array}{c}13.387^{* * *} \\
{[4.364]}\end{array}$ & $\begin{array}{c}13.176^{* * *} \\
{[4.351]}\end{array}$ & $\begin{array}{c}16.111^{* * *} \\
{[4.698]}\end{array}$ & $\begin{array}{c}16.187^{* * *} \\
{[4.691]}\end{array}$ & $\begin{array}{c}14.151^{* * *} \\
{[4.369]}\end{array}$ & $\begin{array}{l}8.843^{*} \\
{[4.566]}\end{array}$ & $\begin{array}{c}10.419^{* *} \\
{[4.203]}\end{array}$ & $\begin{array}{c}13.951 * * * \\
{[4.873]}\end{array}$ & $\begin{array}{c}13.137^{* * *} \\
{[4.490]}\end{array}$ & $\begin{array}{l}8.473^{*} \\
{[4.510]}\end{array}$ & $\begin{array}{c}11.328^{* * *} \\
{[4.128]}\end{array}$ \\
\hline Observaciones & 288 & 273 & 273 & 273 & 273 & 273 & 273 & 273 & 270 & 270 & 256 & 256 & 258 & 258 & 246 & 246 \\
\hline R-cuadrado & 0.525 & 0.539 & 0.828 & 0.861 & 0.894 & 0.895 & 0.894 & 0.896 & 0.898 & 0.897 & 0.915 & 0.916 & 0.901 & 0.901 & 0.921 & 0.921 \\
\hline EF por país & No & No & $\mathrm{Si}$ & $\mathrm{Si}$ & $\mathrm{Si}$ & $\mathrm{Si}$ & $\mathrm{Si}$ & $\mathrm{Si}$ & $\mathrm{Si}$ & $\mathrm{Si}$ & $\mathrm{Si}$ & $\mathrm{Si}$ & $\mathrm{Si}$ & $\mathrm{Si}$ & $\mathrm{Si}$ & $\mathrm{Si}$ \\
\hline EF por año & No & No & No & $\mathrm{Si}$ & $\mathrm{Si}$ & $\mathrm{Si}$ & $\mathrm{Si}$ & $\mathrm{Si}$ & $\mathrm{Si}$ & $\mathrm{Si}$ & $\mathrm{Si}$ & $\mathrm{Si}$ & $\mathrm{Si}$ & $\mathrm{Si}$ & $\mathrm{Si}$ & $\mathrm{Si}$ \\
\hline
\end{tabular}

Errores estándar entre corchetes

${ }^{* * *} p<0.01,{ }^{* *} p<0.05,{ }^{*} p<0.1$ 